\title{
Lusioersily
}

\section{A study of developments and applications of mixed reality cubicles and their impact on learning}

Uhomoibhi, J., Onime, C., \& Wang, H. (2019). A study of developments and applications of mixed reality cubicles and their impact on learning. International Journal of Information and Learning Technology, 37(1/2), 1531. https://doi.org/10.1108/IJILT-02-2019-0026

Link to publication record in Ulster University Research Portal

\section{Published in:}

International Journal of Information and Learning Technology

\section{Publication Status:}

Published online: 16/09/2019

DOI:

10.1108/IJILT-02-2019-0026

\section{Document Version}

Author Accepted version

\section{General rights}

Copyright for the publications made accessible via Ulster University's Research Portal is retained by the author(s) and / or other copyright owners and it is a condition of accessing these publications that users recognise and abide by the legal requirements associated with these rights.

\section{Take down policy}

The Research Portal is Ulster University's institutional repository that provides access to Ulster's research outputs. Every effort has been made to ensure that content in the Research Portal does not infringe any person's rights, or applicable UK laws. If you discover content in the Research Portal that you believe breaches copyright or violates any law, please contact pure-support@ulster.ac.uk. 


\title{
A Study of Developments and Applications of Mixed Reality Cubicles and Their Impact on Learning
}

\author{
J. Uhomoibhi \\ Artificial Intelligence Research Group, Ulster University, Northern Ireland, UK \\ C. Onime \\ International Centre for Theoretical Physics, Trieste, Italy \\ H. Wang \\ Artificial Intelligence Research Group, Ulster University, Northern Ireland, UK
}

\begin{abstract}
Purpose - This paper reports on developments and applications of mixed reality cubicles and their impacts on learning in higher education. This paper investigates and presents the cost effective application of augmented reality (AR) as a mixed reality technology via or to mobile devices such as head-mounted devices, smart phones and tablets. Discuss the development of mixed reality applications for mobile (smartphones and tablets) devices leading up to the implementation of a mixed reality cubicle for immersive three dimensional (3D) visualizations.

Design/methodology/approach - The approach adopted was to limit the considerations to the application of AR via mobile platforms including head-mounted devices with focus on smartphones and tablets, which contain basic feedback -to-user channels such as speakers and display screens. An AR visualization cubicle was jointly developed and applied by three collaborating institutions. The markers, acting as placeholders acts as identifiable reference points for objects being inserted in the mixed reality world. Hundreds of participants comprising academics and students from seven different countries took part in the studies and gave feedback on impact on their learning experience.

Findings - Results from current study show less than $30 \%$ had used mixed reality environments. This is lower than expected. About $70 \%$ of participants were first time users of mixed reality technologies. This indicates a relatively low use of mixed reality technologies in education. This is consistent with research findings reported that educational use and research on augmented reality is still not common despite their categorization as emerging technologies with great promise for educational use.

Research limitations/implications - Current research has focused mainly on cubicles which provides immersive experience if used with head-mounted devices (goggles and smartphones), that are limited by their display/screen sizes. There are some issues with limited battery lifetime for energy to function, hence the need to use rechargeable batteries. Also, the standard dimension of cubicles does not allow for group visualizations. The current cubicle has limitations associated with complex gestures and movements involving two hands, as one hand are currently needed for holding the mobile phone.

Practical implications - The use of mixed reality cubicles would allow and enhance information visualization for big data in real time and without restrictions. There is potential to have this extended for use in exploring and studying otherwise inaccessible locations such as sea beds and underground caves.

Social implications - Following on from this study further work could be done to developing and application of mixed reality cubicles that would impact businesses, health, and entertainment.

Originality/value - The originality of this paper lies in the unique approach used in the study of developments and applications of mixed reality cubicles and their impacts on learning. The diverse composition in nature and location of participants drawn from many countries comprising of both tutors and students adds value to the present study. The value of this research include amongst others, the useful results obtained and scope for developments in the future.
\end{abstract}

Keywords Mixed Reality, Cubicles, CAVE, Mobile Computing, Learning impacts

Paper type Research paper 


\section{Introduction}

Humans typically perceive and relate with their surrounding environment using the five physiological senses of sight, smell, touch, sound and taste, although sight, sound and touch are more readily used. Mixed Reality technology has the potential to offer richer information, increase learner engagement and to improve the educational offering for different categories of learners. Augmented reality as the leading technology has the capability to engage the user in an enhanced perception of the surroundings as well as the possibility to act as a bridge towards different types of contents encompassing text, audio, video. AR is characterized by the combination of real and virtual components and by interaction in real time (Azuma, 1997; Milgram and Kishino, 1994;).

The portability of technology over the years, has seen a shift from the use of heavy backpaks and associated displays to the use of light glasses connected to mobile devices such as Google Glass (Google Glass, 2013) and the futuristic AR contact lense. Most recently, the use of Microsoft's Hololens platform (Microsoft Hololens) has resulted in new levels of immersion to a holographic AR reality experience, with the help of a head-mounted display embedding all the hardware (Cheok et al, 2004; M. Ostanin, A. Klimchik, 2018; Lang et al, 2019).

Reality may be considered as a state of having existence, substance or objects that may be actually experienced and/or seen (Onime and Abiona, 2016), while virtuality may be considered as having a non-realistic (or abstract) view of objects, that is opposite of an idealistic, realistic or notional view. This opposing relationship between reality on the one hand and virtuality on the other hand is illustrated in Figure 1, where reality is at one extreme of a continuum while virtuality, better known as Virtual Reality (VR), is at the opposite extreme and in-between them is the mixed-reality environment (Onime et. al., 2016).

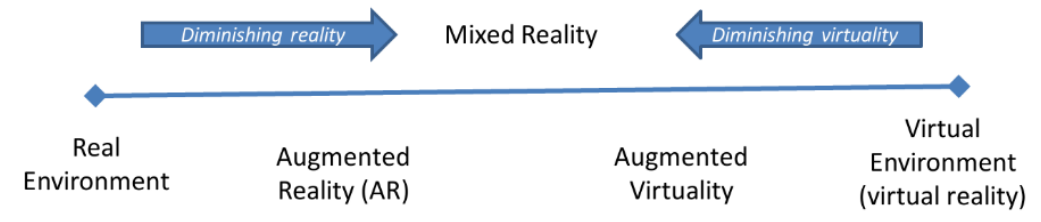

Fig. Reality-Virtuality Continuum. Adapted from (Milgram et. al. 1994)

Traveling along the continuum from left to right represents diminishing reality (or reduction in real objects) and increasing virtuality (increase in virtual objects) resulting in the complete absence of real objects at the virtual end. In other words, at the VR end, the environment is completely made up of virtual objects. Two kinds of mixed reality environments are present in the continuum: Augmented Reality (AR), where the environment is predominantly composed of real objects and Augmented Virtuality (AV) where it is made up of virtual objects. In AR, the goal is not to exclude the real objects (as in VR) but to blend additional or computer generated information into the real world. While in AV, the goal is to blend real objects (data or information from real world) into a computer generated environment (Onime et. al., 2016). From Figure 1 , it is not difficult to imagine a centroid point of the continuum where it is no longer possible to distinguish the real world from the virtual world (Milgram et. al. 1994), located hypothetically between AR and AV that represent a situation of balance, or equal number of real and virtual objects,

In general, the environment described by the continuum may be simplified as the 
integration of real and virtual objects as shown in Equation 1.

$$
\mathrm{E}=\int(R+V)
$$

Where $\mathrm{E}$ represents the environment, $\mathrm{R}$ the set of real objects and $\mathrm{V}$ the set of virtual objects.

As earlier discussed, E may be conditionally grouped into distinct environments as follows:

$$
E=\left\{\begin{array}{cc}
E_{R} ; & \text { if } V=0 \\
E_{A R} ; & \text { if } R>V \\
E_{A V} ; & \text { if } R=V \\
E_{R} ; & \text { if } R<V \\
E_{V R} ; & \text { if } R=0
\end{array}\right.
$$

Where $\mathrm{E}_{\mathrm{R}}, \mathrm{E}_{\mathrm{AR}}, \mathrm{E}_{\mathrm{c}}, \mathrm{E}_{\mathrm{AV}}$ and $\mathrm{E}_{\mathrm{VR}}$ represent the Real, $\mathrm{AR}$, centroid, $\mathrm{AV}$ and VR environments respectively, each of which may be individually expanded from Equation 1. Eliminating the extremities from Equation 2 then results in the mixed reality environment as show in Equation 3.

$$
E_{M R}=\left\{\begin{array}{cl}
E_{A R} ; & \text { if } R>V \\
E_{C} ; & \text { if } R=V \\
E_{A V}, & \text { if } R<V
\end{array}\right.
$$

Where, $\mathrm{E}_{\mathrm{MR}}$ represents the mixed reality environment.

In practice, the solution of Equations 3 and 1 is simplified during the creation of mixed reality environments by introducing / using special place holders known as markers to indicate the relative entry-points (or positions) and/or orientation of other (to be introduced) objects within environment. For example, in the visual form of AR, the marker is a graphically visible image that should be recognised at run-time from different distances, resolutions and angles.

That is,

$$
E_{A R}=\int\left(R+R_{P}\right)
$$

Where $\mathrm{R}_{\mathrm{p}}$ is the set of real place-holders used for insertion of virtual objects

$E_{A V}=\int\left(V_{P}+V\right)$

Where $V_{p}$ is the set of virtual place-holders used for insertion of real objects. Ec is simply the special case of either Equation 4 or 5 when the cardinality of both sets (under the integral sign) are equal.

\subsection{Virtual Reality (VR)}

A broad definition of VR portrays it as a technology that attempts to provide 3D interactions with a computer in new ways with emphasis on the heightened use of the human senses of sight, sound and touch. For example, spatialized sound may be used to 
provide direction such as sound growing louder as the user approaches (Zahorik, 2002). While, a narrower definition describes $\mathrm{VR}$ as a 3D computer-generated simulation oriented environment that allows users to interact at various levels in a more natural manner using interface devices and peripherals such as 3D eye-wear and trackers [9]. For example, haptic devices allow users (with a VR environment) to touch surfaces, grasp and move virtual objects, possibly obtaining feedback/reactions them (Basdogan et. al., 2000; Tan and Pentland, 1997).

In VR, the user undergoes an immersion or the psychological experience of loosing himself in the computer (digitally) generated environment (virtual space or world) that may be sometimes modeled after or based on an existing (real) environment. Although, in such virtual world(s), everything is possible as typical laws of physics such as gravity and time may be modified or eliminated completely and the users can (within its confines) overcome limitations that were previously imposed by the physical world (Loscos et. al. 2003).

VR has been classified into non, semi and fully immersive systems, according to the degree of immersion experienced by the users (Fox et. al., 2009). In non-immersive VR systems, users do not have a stereo view and/or experience of the virtual environment. Semi-immersive VR systems provide a bigger view of the computer generated environment mainly through use of a large screen device or special eye-wear (or goggles), commonly combined with special input devices such as wands, gloves or controllers. Fully-immersive VR systems provide a total (3D) view of the computer generated environment obtained using multiple large screen devices or special eye-wear along with special input devices such as touch-screens, wands, gloves and controllers.

Figure 2 shows two different examples of VR environments, the first rep- resents an indoor environment with various bits of furniture including chairs, a sofa and a painting, while the second is an outdoor view of a well developed water-front.

In many VR systems as discussed in the literature review section 2, full immersion occurs when all references to the real world environment are completely removed by housing the user in specially designed CAVE environments(s) or using special head- mounted displays (HMD) (helmet devices with mounted displays) for mobility. This paper discusses obtaining similar heightened (fully) immersive experience using mixed-reality technology and Section 3 presents the development, limitations of a fully immersive mixed-reality cubicle and results of a study on familiarity with mixed reality technologies at two different academic institutions, while Section 4 concludes the paper. 

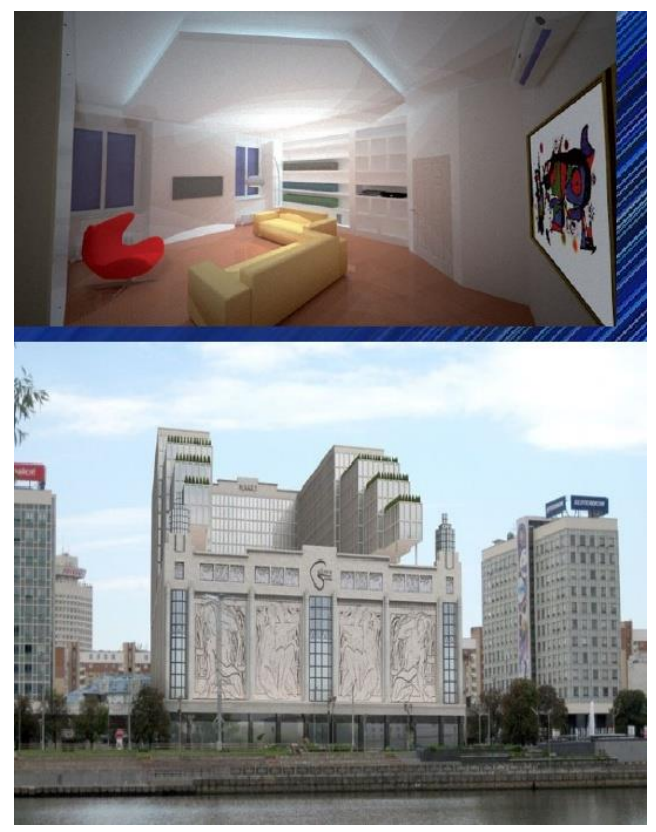

Fig. 2 Examples of VR environments. (Santa’s Company, 2013)

\section{Literature Review}

VR and mixed-reality are two technologies that are changing the future directions of ubiquitous computing and there are already, many diverse applications of VR technology in various sectors: For example, VR has been used as a plat- form to study differences in human behaviour within controlled environment and the real physical world (Santa's Company, 2013). It has also been used as a platform for teaching specialized procedures to pilots (Pausch et. al., 1992) and doctors (O'Toole et. al, 1998) without the associated risks involved in a real environment.

Mixed reality applications now surround us everywhere in education, at home and in industry. They are most obviously in video games and entertainment, but also in live events, in retail, education, healthcare and engineering (Quint, 2015; Bellini et al, 2016; The Ford Motor Company, 2017). They are used for information visualization, remote collaboration, humanmachine-interfaces, design tools as well as education and training (Scholz and Smith, 2016; Bacca et al, 2015).

Mixed Reality combines the real world and the virtual world into one user experience, which significantly helps to extend opportunities for enhanced real learning (Lee, 2012; Guo, 2015). In the face of rapid technological developments with increasing student number abd diversity of needs, there is the search for new ways to teach, it could be argued that AR has the potential pedagogical applications to meet some of the needs.

In the education sector, there are on-line resources that use non-immersive VR related techniques to provide several chemistry laboratory experiments/exercises, as well as, simulation of a chemistry laboratory through use of rich media powered by JavaScript (Georgiou et. al, 2007). In civil engineering, building technology and architecture, VR based prototyping is also commonly used to provide a 3D view (or 3D printed model) of objects with varying levels of abstraction (Cecil and Huber, 2010).

Virtual reality is used to provide the interactive display of 3D objects in the gaming industry 
(massive on-line role playing games) and scientific research work especially those involving modeling and simulation. However, in cases of on-line use, the full potential (or immersive nature) of VR is limited by the traditional User Interface (UI) of end-user computers.

Just like VR, mixed reality technology has been used for diverse applications including the reconstruction of heritage (Huang et. al., 2009), the training of operators in specialized processes (Henderson and Feiner, 2009), system maintenance (Schwald and de Laval, 2003), augmenting visits to muse- ums and historic buildings (White et. al., 2004) and for medical training (Albrechta et. al., 2013). Mixed reality technology provides the opportunities to combine learning and entertainment in new ways especially suited for laboratory and classroom (Davidsson et. al. 2012). For example, (Billinghurst et. al., 2001) discussed a mixed reality system for augmenting a normal story book with 3D animations of the characters. While, (Loscos, 2003) discussed a mixed reality framework for the construction and manipulation of photo-realistic virtual worlds specifically for educating learners about cultural heritage, architectural design and urban planning. In engineering, (Andujar et. al., 2011) discussed the augmentation of remote laboratories, while (Onime et. al., 2014) and (Onime et al, 2015) presented laboratory experiments based on mixed reality tools/technologies.

\subsection{Cave Automatic Virtual Environment (CAVE)}

In most implementations of CAVEs, the walls (including floor and ceiling) are replaced by large (wall-sized) displays or projection screens arranged such that the computer generated (virtual) environment is projected all around the user. Within CAVEs, VR systems also have to track and respond to, the user's physical orientation, movements and gestures. Sometimes, this may involve the use of special hand-gloves or body suits suitable for tracking movements in very fine detail. At other times, this may involve the use of suitable sensors. A good example is the CAVE room-sized VR system of (Beckman Institute Illinois Simulator Laboratory, 2013). Another example is the Wall-sized Interaction with Large Datasets (WILD) room (Beaudouin-Lafon et. al., 2012). Where a wall-sized display is combined with a multitouch table and various mobile devices specifically to help scientists collaborate on the analysis of large and complex datasets (Onime and Uhomobhi, 2016). In WILD, the CAVE room could be used by a group of microbiologist (co-located inside the CAVE) to study how one molecule docks with another and interactively and seamlessly switch between several 3D representations, different molecular models, online databases, websites and research articles along with the ability to collaborate with colleagues in remote locations (Beaudouin-Lafon et. al., 2012).

\subsection{Immersive Mixed Reality Environments}

Immersive mixed reality environments offer a different approach to reproducing reality or embodied presence (Nakevska, 2012). The user is exposed to a multi- dimensional environment developed from a heterogeneous composition of technologies including sensors, augmented reality, augmented virtuality supported by processing applications and components that manage the use of contextual information without exclusion of the real-physical environment. Similar to CAVEs which focus on virtual worlds, the immersive mixed reality environment aims to create a "fantasy" world where the user is engaged using multisensory augmentations of the surrounding environment. Unlike CAVEs, immersive mixed reality environments are not restricted to a single physically enclosed location. They may be expanded or moved along with the user thanks to the use of multiple geographically displaced markers. For example, museums may associate unique markers to a sequence of displayed exhibits spread out across several rooms and corridors that would provide an immersive mixed reality environment useful for providing more information. (Nakevska, 2012) documents an immersive 
mixed reality environment that allows users to immersively explore six scenes from the book "Alice in Wonderland".

\subsection{Mixed reality and mobile devices}

The Augmented Reality (AR) form of mixed-reality is already present in many every-day applications, that are location or context aware, including the live-television broadcast of sports events (Azuma et. al, 2001) as it provides new ways of showing relationships and connections in the real world. (Uhomoibhi et. al., 2011) and (Andujar et. al., 2011) show the use of augmented reality in education and (FitzGerald, 2012) reported examples of AR applications from specific domains such as architecture and tourism, that engage the user in an exploratory role (like in games) aimed at the discovery of additional material or content.

This paper limits its considerations to the application of AR via (or to) mobile platforms including head-mounted devices, smart-phones and tablets, focusing on the latter two as most smart-phones and tablet (or mobile) devices contain three basic feedback-to-user channels which are sound speaker(s), a display screen and the ability to vibrate, which may be used for providing auditory, visual and haptic based AR respectively. Mobile devices also contain one or more of the following sensors: microphone, multi-touch input (display), camera, location (gps), accelerometer (for acceleration, rotation or orientation), ambient light level, which may be used to aid the augmentation process. For example, movements, gestures, physical orientation (roll, height, shaking) of the mobile device can be translated into powerful Human Computer Interface (HCI) interactions within a mixed-reality environment.

Many of the existing examples of mixed-reality on mobile platforms focus on using AR in providing passive information (text, audio and video overlays) to users based on input from sensors about physical location, movement and gestures. However, other works such as (Onime, Uhomoibhi and Pietrosemoli, 2015) document the use of Augmented Virtuality (AV) on mobile devices for estimating power output of solar panels. While other works including (Onime, Uhomoibhi and Zennaro, 2014) and (Onime, Uhomoibhi and Radicella, 2015) show the use of mobile AR in education.

\section{Methodology}

\subsection{Mixed Reality Visualization Cubicles}

A mixed reality visualization cubicle may be created using a spatial arrangement of multiple markers. One or more AR markers are placed on each wall of the cubicle and each one provides a windowed view of the virtual environment. For example, a wall may have a single large (A3 or bigger) image or a set of smaller (A4) images. 


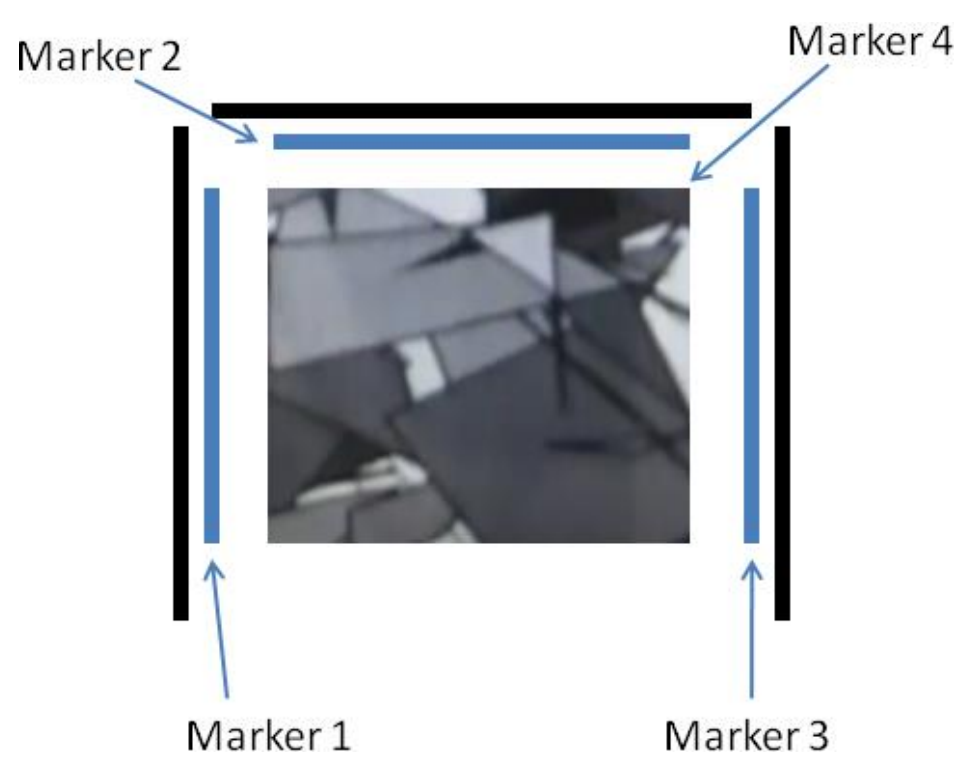

Fig. 3 AR immersive cubicle.

Figure 3 shows the AR visualization cubicle jointly developed by Santa's Co (a software development company from Reggio Emilia, Italy), the Ulster University (UU) and the International Centre for Theoretical Physics (ICTP). The semi-immersive AR environment (cubicle) is composed of four large A3 markers, while three were positioned vertically, each on a separate wall (left, right and front from perspective of a user) to cover a $180^{\circ}$ horizontal angle; the fourth was placed horizontal on the floor to cover a $90^{\circ}$ vertical angle. That is, using this configuration, the cubicle may be used to provide a wide-angle seamless $180 \circ$ view of the virtual world in the horizontal direction seamlessly combined with a $90 \circ$ angle in the vertical direction.

\subsection{Mixed-reality Augmentation Markers}

The marker is a type of place holder located within the environment that acts as an identifiable reference point for insertion of objects in the mixed reality (combined) world. In mobile computing, QR codes are a good example of markers. In its basic format, the visualisation of a two dimensional $Q R$ code using a suitable application ( $Q R$ reader) would cause the opening of a pre-determined Uniform Resource Locator (URL). For mixed-reality systems, The use of QR codes or other objects as markers is definitely more complex as on identification of a marker, the mixed-reality software application visually overlays it with a computer generated object typically catering for aesthetic aspects such as scale, angular orientation and perspective.

Generally, each mixed-reality software application typically contains a representation of its relevant markers that are used for high-speed marker recognition 


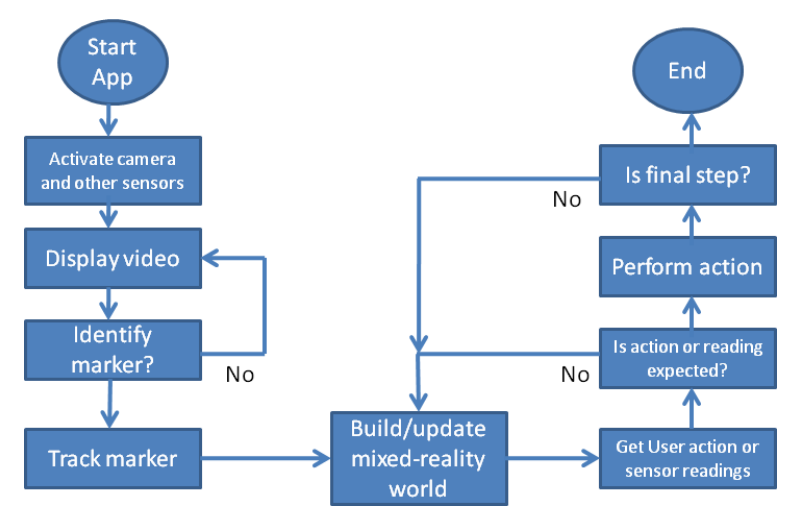

Fig. 4 Technical flowchart for video see-through augmented reality on mobile devices [32]

The representations may also include some additional information that facilitate the identification of markers at different distances, resolutions and angles from the camera. Runtime processing in the software involves the real- time decomposition of images followed by partial grey-scale pattern matching against the stored representations; and overlay of each identified markers with the object it represents (Onime, Uhomoibhi and Wang, 2016). Shapefiles definitions of represented objects are used to facilitate the $3 \mathrm{D}$ rendering by a suitable graphics library or engine that also provide the ability to scale them.

Visual markers in AR could be made from arbitrary/normal patterns, real physical objects, 3D models and even photographic images. The low-computational power of mobile devices has implications for high-speed image processing (detection) required for tracking a marker. In a technique used in mobile AR, the marker image is decomposed into unique set(s) of simple shapes and angles, which is then registered or encoded within the AR application as the marker (Onime, Uhomoibhi and Radicella, 2015).

The markers employed for the mixed-reality cubicle discussed in this paper were computer generated abstract patterns composed of random polygons in greyscale colour. There are already reports of markerless augmentation of complex 3D objects using geometrical shape combined with colour edge information (Petit et. al., 2013), wireless sensors and/or orientation/location (Genc et. al., 2002), with some limitations in accuracy.

\subsection{Creating mobile Augmented Reality ( $m A R$ ) software}

See-through augmented reality on mobile devices Figure 4 shows the technical flow-chart for the sequence of steps implemented in a typical mixed reality (AR) application software. As shown, several distinct and complex software processing steps/stages are required in AR applications, these include managing hardware-sensors such as a hardware camera device (required for capturing a view of the real-world), image processing/detection (required for recognising markers), image rendering/texturizing (required for introducing virtual objects into the view of the real world) and a real-time event-driven programming model, which is required for managing user input and interactions between real-objects, virtual-objects and end-user (Onime, Uhomoibhi and Radicella, 2015).

The process of creating mixed-reality applications on mobile devices has benefited from the introduction of standard Application Programming Inter- faces (API), frameworks and Software Development Kits (SDK) for various mobile-device platforms. For example, developing software for smart-phones running the Android Operating System (Android) depend on the free Android SDK tools available for various software development environment (Fiawoo and Sowah, 2012). Using frameworks such as the Android SDK simplify the software 
development process because they include standardized APIs for a wide range of hardware sensors including accelerometers, gyroscopes, proximity sensors, barometers, as well as, for handling input/output from touch-screen displays (Android Developers, 2014) and abstract hardware while also compensating for inconsistent behaviour by different devices (for example, poor resolution due to distance, motion blur and poor lighting/contrast situations) (Mutholib et. al., 2012). The Android SDK already contains some limited image processing functionality that is used exclusively for Face Detection, but this is not usable for AR as it lacks the ability to register arbitrary images/patterns for detection (Onime, Uhomoibhi and Radicella, 2015), however, there are several libraries or engines that provide 3D capabilities on Android platforms. (Kim et. al., 2014) and (Wang et. al., 2010) as well as other authors have used the "Unity3D" (game) engine for developing educational applications, while, other authors including (Sobota et. al., 2013) and (Xiao and Lifeng, 2014) have combined the Vuforia AR library with other engines. Typically, in rendering, the real-time distance between a marker and camera lens, as well as, the relative angular orientation of the mobile device (obtained possible from accelerometer sensor) are important in computing the adequate scale and perspective of rendered objects.

There are several commercial high-level SDKs for performing augmented reality on mobile platforms and a few of them are free for non-commercial use. The Android applications presented here were developed by combining the Android SDK with a 3rd party image-processing SDK and another 3D rendering library/engine. In the future, it is possible that the free Android SDK would eventually include suitable image-processing and 3D rendering capabilities and maybe a dedicated framework/API for AR.

Obtaining data from sensors using the Android SDK is a relatively straight forward process as documented in [2] and it is sometimes possible to computationally derive functional data from sensors. For example, the common accelerometer sensor works by detecting the inertia of a suspended mass under the influence of acceleration and because the mass is subjected to gravitational force, its relative position during acceleration may be used to derive a tilt angle based on simple trigonometric operations.

Consider the 3-axis accelerometer device shown in Figure 5a, which is com- posed of elastic elements and a suspended mass. When the device is not subject to acceleration and the suspended mass (or body) is at rest or at a zero-point.

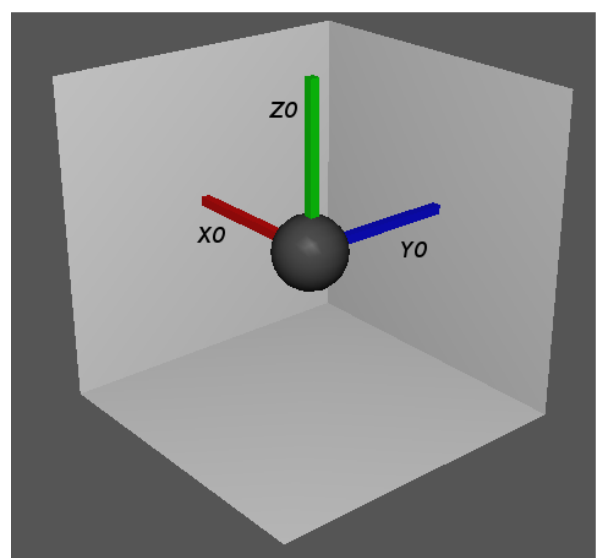

(a) No acceleration

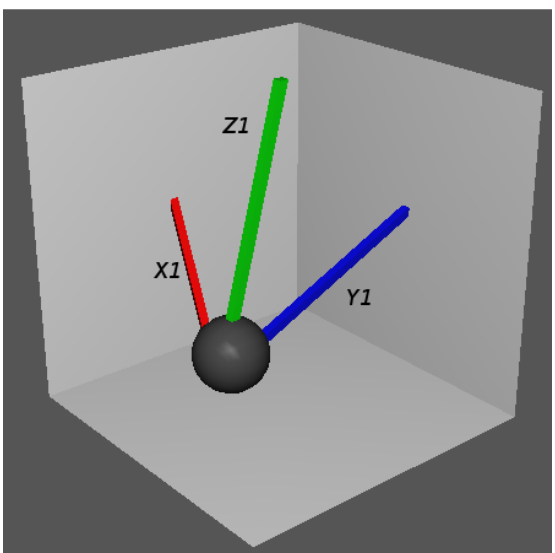

(b) Under acceleration

Fig. 5 Accelerometer mass

The readings or values from the 3 elastic elements at this zero point may be represented by $\mathrm{X} 0, \mathrm{Y} 0, \mathrm{Z} 0$ respectively. 
When the same accelerometer sensor is subject to an acceleration as shown in Figure 5b, the mass is displaced from its zero point and the readings from the elastic elements may be represented by $\mathrm{X} 1, \mathrm{Y} 1$ and $\mathrm{Z} 1$ respectively.

A reasonably accurate single-axis tilt-angle of the mass with respect to the original position (Figure 5a) may be determined mathematically from the trigonometric (tangent) relationship of the other two axis (elastic elements) (Hsu et. al., 2013).

That is, calculating the tilt angle of the $\mathrm{X}$ axis would be carried out as follows:

$$
\tan \theta_{\mathrm{x}}=\frac{\mathrm{Z} 1}{\mathrm{Y} 1}
$$

or

$$
\theta_{\mathrm{x}}=\arctan \left(\frac{\mathrm{Z} 1}{\mathrm{Y} 1}\right)
$$

In equation 6 and 7, $\theta_{\mathrm{x}}$ is in radians.

In practice, the readings from the accelerometer could be quite erratic and it is usual to stabilize the values using a filtering factor $\mathrm{k}$ such that Equations 6 and 7 become

$$
\tan \theta_{\mathrm{x}}=\frac{\mathrm{Z} 1(\mathrm{k})+\mathrm{Z} 0(1-\mathrm{k})}{\mathrm{Y} 1(\mathrm{k})+\mathrm{Y} 0(1-\mathrm{k})}
$$

and

$$
\theta_{\mathrm{x}}=\arctan \left(\frac{\mathrm{Z} 1(\mathrm{k})+\mathrm{Z} 0(1-\mathrm{k})}{\mathrm{Y} 1(\mathrm{k})+\mathrm{Y} 0(1-\mathrm{k})}\right)
$$

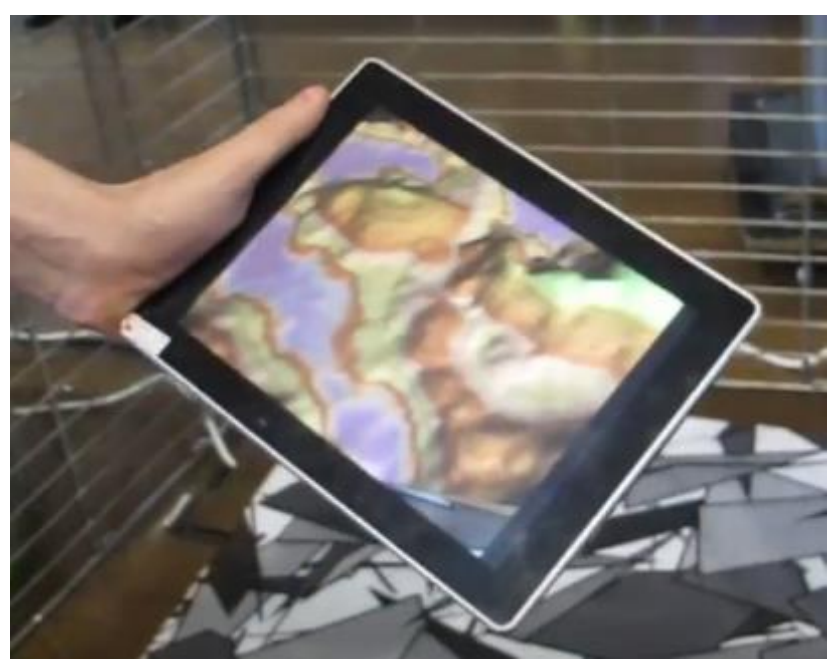

Fig. 6 mobile device view inside immersive mixed-reality (AR) cubicle.

Practically the value of the filtering factor was determined as $0.98 \mathrm{f}$ (where $\mathrm{f}$ enforces IEEE single-precision float). Equation 9 may be implemented by the following pseudo-code function, which would accept a 3-axis accelerometer reading and return the corresponding tilt angle values in degrees. 


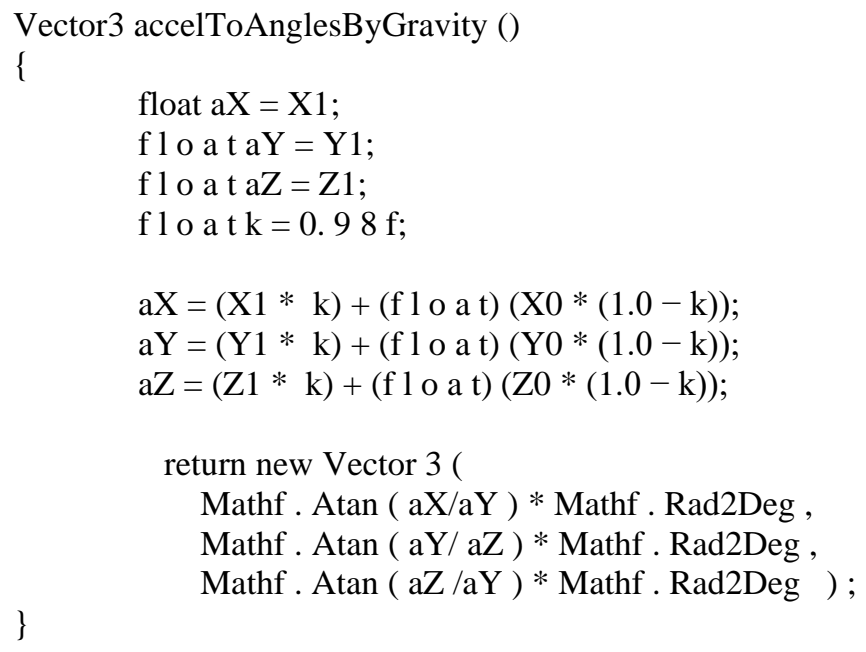

The development of a mixed-reality visualization cubicle involved the spatial placement of markers on each face of a cubicle as shown in Figure 3. Where each marker is part of a coordinated set and individually provides a windowed view of a virtual environment as shown in Figure 6.

\section{Results and Discussion}

\subsection{Applications}

VR and mixed reality technologies are already widely applied in sectors ranging from medicine, entertainment, education and interactive guides, nature and earth science.

Within the cubicle described in this paper, the spatial arrangement of markers provided a wide-angle $\left(180^{\circ}\right.$ horizontal $+90^{\circ}$ vertical) exploration that was used in an educational context for the interactive visualisation of geospatial data representing landforms. This form of application is equally useful for conducting interactive visits to cities or other remote sites/locations in a manner that allows a user to travel along streets and also experiencing the sights, sounds and smells. The latter would be possible with coordinated use of specialized sensors that release precaptured scents.

Mixed-reality based tools are gaining grounds as a new class of "Big Data" visualisation tools capable of providing interactive exploration for growing research outputs/data, large or big datasets resulting from simulations and physical experiments such as the LHC (CERN, Geneva) or Genome related sequencing (Onime and Uhomobhi, 2016). Thanks to its wideangle capability, a mixed reality cubicle is well positioned to play a expanded role in the visualisation of "Big Data". In addition, when combined with a suitable communication medium such as the INTERNET, two mixed reality cubicles could be used for the collaborative visualization of research data by researchers across geographical distances.

\subsection{Familiarity with mixed reality technology}

Anonymous feedback was obtained from 174 academicians (researchers and students). Demographically, participants were from 7 different countries al- though primarily from two institutions. That is, 154 were from the Obafemi Awolowo University, Nigeria and the Addis Ababa University, Ethiopia; while the remaining 20 were from other institutions in 7 different countries. The consenting adult volunteers, who participated without incentives, risks and disadvantages in the international study were informed of the purpose, confidentiality of the study and the intended use of the collected data.

Table 1 shows distribution of respondents by countries (of institution). The survey based study was conducted on-site at both the AAU (Ethiopia) 
Table 1 Participation overview by country and institution

\begin{tabular}{|l|c|c|}
\hline Country & Respondents & Institutions \\
\hline Algeria & 1 & 1 \\
Cameroon & 1 & 1 \\
Ethiopia & 86 & 1 \\
Italy & 5 & 1 \\
Nigeria & 76 & 5 \\
Spain & 1 & 1 \\
United Kingdom & 4 & 2 \\
\hline
\end{tabular}

and OAU (Nigeria), while participation from other institutions/countries were remote.

Table 2 shows resulting distribution of the study population across the selected disciplines of natural sciences and About $64 \%$ were undergraduate students and only $16 \%$ were female.

Table 2 Summary of respondents

\begin{tabular}{|l|c|}
\hline Profile & Percentage (\%) \\
\hline Gender & 79.31 \\
Male & 18.97 \\
Female & 01.72 \\
Data not provided & \\
\hline Departments & 07.47 \\
Computational Science & 33.33 \\
Computer Science & 04.02 \\
Computer Engineering & 27.01 \\
Engineering & 04.02 \\
Mathematics & 21.84 \\
Physics & 02.31 \\
Data not provided & \\
\hline
\end{tabular}

As shown in Table 3, participants were asked if they have used mixed reality (AR) tools/technology.

Table 3 Respondent's familiarity with mixed reality technology

\begin{tabular}{|l|c|}
\hline Response & Percentage (\%) \\
\hline No & 39.08 \\
\hline Don't think so & 10.34 \\
\hline Don't know & 21.84 \\
\hline Maybe & 10.92 \\
\hline Yes & 17.82 \\
\hline
\end{tabular}

The collected data show less than $30 \%$ had used mixed reality environments which is lower than expected. It is probably that participants may have failed to recognize their 
encounters mixed reality technology from other sec- tors such as the entertainment industry. However, this is a clear indication of the relatively low use of mixed reality technologies in education.

Although, the mean age was between 21 - 24 years, about $70 \%$ of respondents were also first-time users of mixed reality technologies. The results obtained are consistent with the findings of (Martin et. al., 2011) and (Nincarean et. al., 2013) that educational use and research on augmented reality is still not common despite their continued classifications as emerging technologies (Wenguang, 2011) with enormous promise for educational use (New Media Consortium, 2014; Nincarean et. al., 2013).

It is possible that mixed reality cubicles as discussed in this paper would improve knowledge about both AR and VR technologies (Onime, Uhomoibhi and Wang, 2016).

\subsection{Limitations}

The cubicle provides a fully immersive experience if used with suitable AR goggles or headmounted devices. Tablets and normal smart-phones alone provide a windowed semi-immersive view limited by their display/screen sizes.

The mobile technology based viewing devices used within the cubicle may experience issues related to poor visibility in the presence of strong ambient light. This has been reported by other authors and can be mitigated by keeping ambient lighting at normal room levels (FitzGerald, 2012; Onime and Uhomobhi, 2016). The mobile viewing devices may only be used for limited duration as they depend on rechargeable batteries for energy to function.

Within the current version of the cubicle, complex gestures or movements involving twohands is not yet possible as users would hold the mobile device in one hand and can only perform gestures with the other hand.

The standard dimensions of a typical cubicle does not allow for group visualizations or use. Even if extra large cubicles are used, users usually work individually or in groups sometimes with individual viewpoints of a common physical object or marker (Billinghurst, Kato and Poupyrev, 2001).

\section{Conclusion and future work}

This paper has presented the implementation of a mixed-reality visualization cubicle based on mobile Augmented Reality (AR) technology. The implementation uses spatially arranged AR markers to provide features typically avail- able within Virtual Reality (VR) CAVEs. Costeffectiveness is obtained by developing mixed reality applications for commonly available mobile Information and Communication Technology (ICT) devices (smart-phone and tablet) as the hardware platforms are readily affordable/available to all. Future work include the creation of an Experience Lab by the Artificial Intelligence and Ap- plications Research Group at Ulster University, that involve the deployment of several enhanced mixed-reality visualization cubicles at Ulster University and the ICTP. Enhancements would involve using suitable head and chestmounted mobile devices for visualizing and exploring fully-immersive AR environments and supporting joint visualizations and explorations by users in different geographically separate locations. Applications for the Experience Lab would include creating visual-experiential presence during videoconferencing meetings, immersive exploration of cities or tourism sites and the creation and use of "smart" AR markers based on Internet of Things (IoT) or similar sensors.

The Artificial Intelligence and Applications Research Group at Ulster University has set up an Experience Lab, which includes the deployment of cost effective mixed reality cubicles at Ulster University and the ICTP. Both groups are investigating creating wideangle semi immersive mixed reality environments as discussed in this paper along with fully 
immersive mixed reality environments using suitable head and chest-mounted mobile devices. The latter allows the free use of both hands for gesture based interactions.

In the Information Visualization for Big Data (IVIS4BigData) reference model, multiple researchers in different geographically separate locations are expected to concurrently work together, interactively examining/exploring Big-Data or research data in real-time and without restrictions. Progressing towards the IVSI4BigData model requires research on various techniques for dynamically transforming and streaming fragments of Big-Data to a variety of visualization tools/platforms including the mixed reality cubicle described in this paper. In line with the IVIS4BigData reference model, The mixed reality cubicle would need to be extended for multidisciplinary Computer Supported Group Work (CSCW) based on open standards over various infrastructure including local wireless or mesh networks, the internet and Clouds.

Apart from the above described activities, we foresee the immersive interactive exploration of various datasets from diverse sources within the mixed reality cubicles of the "Experience Lab". For example, geospatial datasets of existing locations (or cities) could be used to provide interactive remote exploration and tourism related experience. Other datasets derived from Internet of Things (IoT) or other sensors could be used for the interactive exploration and study of otherwise inaccessible locations including underground caves, coral reefs or other sea beds and even in some mining related activities.

Acknowledgements: The authors would like to thank the School of Computing, Ulster University; the Telecommunications and ICT for Development (T/ICT4D) Laboratory, ICTP and Santa's Co, Regio-Emilia, Italy.

\section{References}

Albrechta, U., Nolla, C., von Jan, U.: Explore and experience: Mobile augmented reality for medical training. In: C.U. Lehmann, C. Ammenwert, C. Nahr (eds.) MEDINFO 2013: Studies in Health Technologis and Informatics vol 192, pp. 382-386. IMIE \& IOS Press, Copehegen (2013)

Android Developers: Introduction to android. Available from: http://developer.android.com/guide/index.html (2014)

Andujar, J.M., Mejias, A., Marquez, M.A.: Augmented reality for the improvement of remote laboratories: An augmented remote laboratory. Education, IEEE Transactions on 54(3), 492-500 (2011)

Azuma, R.T., 1997. A survey of augmented reality. Presence 6 (4), 355-385.

Azuma, R., Baillot, Y., Behringer, R., Feiner, S., Julier, S., MacInTyre, B.: Recent advances in augmented reality. IEEE Computer Graphics and Applications 21(6), 34-47 (2001)

Bacca, J., Baldiris, S., Fabregat, R., Kinshuk, and Graf, S. "Mobile Augmented Reality in Vocational Education and Training," Procedia Comput. Sci., vol. 75, no. Vare, pp. 49-58, 2015.

Basdogan, C., Ho, C.H., Srinivasan, M.A., Slater, M.: An experimental study on the role of touch in shared virtual environments. ACM Trans. Comput.- Hum. Interact. 7(4), 443-460

(2000). DOI 10.1145/365058.365082. URL http://doi.acm.org/10.1145/365058.365082

Beaudouin-Lafon, M., Huot, S., Nancel, M., Mackay, W., Pietriga, E., Primet, R., Wagner, J., Chapuis, O., Pillias, C., Eagan, J., Gjerlufsen, T., Klokmose, C.: Multisurface interaction in the wild room. Computer 45(4), 48-56 (2012). DOI 10.1109/MC.2012.110

Beckman Institute Illinois Simulator Laboratory: University of Illinois at Urbana.Champaign: Beckman institute illinois simulator laboratory. Available from: http://isl.beckman.illinois.edu/Labs/CAVE/CAVE.html (2013). [Accessed 12 February 2019]

Bellini, H., Chen, W., Sugiyama, M., Shin, M., Alam, S. and Takayama, D., "Virtual \& Augmented Reality: Understanding the race for the next computing platform," Profiles Innov., pp. 1-30, 2016.

Billinghurst, M., Kato, H., Poupyrev, I.: The magicbook - moving seamlessly between reality and virtuality. IEEE Computer Graphics and Applications 21(3), 6-8 (2001) 
Cecil, J.: The creation of virtual learning environments. In: W. Aung, V. Llic, O. Mertanen, J. Moscinski, J. Uhomoibhi (eds.) Innovations 2012: World Innovations in Engineering Education and Research, pp. 263-273. iNEER, Potomac (2012)

Cecil, J., Huber, J.: Virtual prototyping in engineering. In: J. Cecil (ed.) Virtual Engineering, pp. 1-15. Momentum Press, New Jersey (2010)

Cheok, A.D., Goh, K.H., Liu, W., Farbiz, F., Fong, S.W., Teo, S.L., Li, Y., Yang, X., 2004. Human pacman: a mobile, wide-area entertainment system based on phys- ical, social, and ubiquitous computing. Pers. Ubiquitous Comput. 8 (2), 71-81. doi: 10.1007/s00779-004-0267-x.

Davidsson, M., Johansson, D., Lindwall, K.: Exploring the use of augmented reality to support science education in secondary schools. In: Seventh international conference on Wireless, Mobile and Ubiquitous Technology in Education, pp. 218-220. IEEE Computer Society (2012)

Fiawoo, S., Sowah, R.: Design and development of an android application to process and display summarised corporate data. In: Adaptive Science Technology (ICAST) 2012 IEEE 4th International Conference on, pp. 86-91 (2012). DOI 10.1109/ICASTech.2012.6381072

FitzGerald, E., Adams, A., Ferguson, R., Gaved, M., Mor, Y., Thomas, R.: Augmented reality and mobile learning: the state of the art. In: M. Specht, M. Sharples, J. Multisilta (eds.) 11th World Conference on Mobile and Contextual Learning (mLearn 2012), pp. 62-69. CEUR, Helsinki (2012)

Fox, J., Arena, B., Bailenson, J.N.: Virtual reality: A survival guide for the social scientist. Journal of Media Psychology 21(3), 95-113 (2009)

Genc, Y., Riedel, S., Souvannavong, F., Akinlar, C., Navab, N.: Marker-less tracking for ar: a learning-based approach. In: Proceedings. International Symposium on Mixed and Augmented Reality, pp. 295-304 (2002). DOI 10.1109/ISMAR.2002.1115122

Georgiou, J., Dimitropoulos, K., Manitsaris, A.: A virtual reality laboratory for distance education in chemistry 1(11), $337-344$ (2007). URL http://waset.org/Publications? $\mathrm{p}=11$

Google Glass, 2013. https://www.google.com/glass/start/ (accessed 31.07.19).

Guo, Q., "Learning in a Mixed Reality System in the Context of 'Industrie 4.0,"” J. Tech. Educ., vol. 3, no. 2, pp. 92-115, 2015.

Henderson, S.J., Feiner, S.: Evaluating the benefits of augmented reality for task localization in maintenance of an armored personnel carrier turret. In: Proc. IEEE ISMAR- AMH, pp. 135-144. IEEE (2009)

Hsu, C.L., Chou, W.C., Lin, W.Y.: A digital tilt converter for three-axis accelerometers.

In: Consumer Electronics (ISCE), 2013 IEEE 17th International Symposium on, pp. 19-20 (2013). DOI 10.1109/ISCE.2013.6570178

Huang, Y., Liu, Y., Wang, Y.: Ar-view: An augmented reality device for digital reconstruction of yuangmingyuan. In: Proc. IEEE ISMAR-AMH, pp. 3-7. IEEE (2009)

Kim, S.L., Suk, H.J., Kang, J.H., Jung, J.M., Laine, T., Westlin, J.: Using unity 3d to facilitate mobile augmented reality game development. In: Internet of Things (WF-IoT), 2014 IEEE World Forum on, pp. 21-26 (2014). DOI 10.1109/WF-IoT.2014.6803110

Lanier, J.: Virtual reality: the promise of the future. Interactive Learning International 8(4), 275-279 (1992)

Lee, K., "Augmented Reality in Education and Training," TechTrends, vol. 56, no. 2, pp. 13-21, 2012.

Loscos, C., Widenfeld, H.R., Roussou, M., Meyer, A., Tecchia, F., Drettakis, G., Gallo, E., Martinez, A.R., Tsingos, N., Chrysanthou, Y., Robert, L., Bergamasco, M., Dettori, A., Soubra, S.: The create project: mixed reality for design, education, and cultural heritage with a constructivist approach. In: The Second IEEE and ACM International Symposium on Mixed and Augmented Reality, pp. 282-283. IEEE (2003)

Martin, S., Diaz, G., Sancristobal, E., Gil, R., Castro, M., Peire, J.: New technology trends in education: Seven years of forecasts and convergence. Computers \& Education 57(3), 1893-1906 (2011). DOI http://dx.doi.org/10.1016/j.compedu.2011.04.003. URL http://www.sciencedirect.com/science/article/pii/S0360131511000844

Milgram, P., Takemura, H., Utsumi, A., Kishino, F.: Augmented reality: A class of displays on the reality-virtuality continuum. Telemanipulator and Telepresence Technologies SPIE 2351, 282-292 (1994)

Milgram, P., Kishino, F., 1994. A taxonomy of mixed reality visual displays. IEICE Trans. Inf. Syst. 77 
(12), 1321-1329.

Mohammed, S., Sheikh, S., Kota, D., Weigert, D., Behrendt, F., 2019. Mixed reality in production and logistics: Discussing the application potentials of Microsoft HoloLensTM. Procedia Computer Science, Volume 149, 2019, Pages 118-129

Mutholib, A., Gunawan, T., Kartiwi, M.: Design and implementation of automatic number plate recognition on android platform. In: Computer and Communication Engineering (ICCCE), 2012 International Conference on, pp. 540-543 (2012). DOI 10.1109/ICCCE.2012.6271245

Nakevska, M., Hu, J., Langereis, G., Rauterberg, M.: Alice's adventures in an immersive mixed reality environment. In: 2012 IEEE International Symposium on Mixed and Augmented Reality (ISMAR), pp. 303-304 (2012). DOI 10.1109/ISMAR.2012.6402585

New Media Consortium: Horizon report 2014 k-12 edition. Available from: http://cdn.nmc.org/media/2014-nmc-horizon-report-k12-En.pdf (2014). [Accessed 5 February 2019]

Nincarean, D., Alia, M.B., Halim, N.D.A., Rahman, M.H.A.: Mobile augmented reality: The potential for education. Procedia - Social and Behavioral Sciences 103(0), 657 - 664 (2013). DOI http://dx.doi.org/10.1016/j.sbspro.2013.10.385. URL http://www.sciencedirect.com/science/article/pii/S1877042813038305. 13th International Educational Technology Conference

Onime, C., Abiona, O.: 3D mobile augmented reality interface for laboratory experiments. International Journal of Communications, Network and Sys- tem Sciences 09(04), 67-76 (2016). DOI 10.4236/ijens.2016.94006. URL http://dx.doi.org/10.4236/ijens.2016.94006

Onime, C., Uhomobhi, J.: Cost Effective Visualization of Research Data for Cognitive Development Using Mobile Augmented Reality, pp. 35-49. Springer International Publishing, Cham (2016). DOI 10.1007/978-3-319-50070-6 $3 . \quad$ URL http://dx.doi.org/10.1007/978-3-319-50070-6 3

Onime, C., Uhomoibhi, J., Pietrosemoli, E.: An augmented virtuality based solar energy power calculator in electrical engineering. International Journal of Engineering Pedagogy 5(1), 4-7 (2015)

Onime, C., Uhomoibhi, J., Radicella, S.: Mare: Mobile augmented reality based exper- iments in science, technology and engineering. In: M.T.R. Restivo, A. Cardoso, A.M. Lopez (eds.) Online Experimentation: Emerging Technologies and IoT, pp. 209-227. IFSA Publishing, Barcelona, Spain (2015)

Onime, C., Uhomoibhi, J., Wang, H.: Mixed reality cubicles and cave automatic virtual environment. In: The 15th International Conference on Ubiquitous Computing and Communications (IUCC 2016), pp. 1-8. IEEE Conference Publishing Services, Grenada, Spain (2016). DOI 10.1109/IUCCCSS.2016.8

Onime, C., Uhomoibhi, J., Zennaro, M.: A low cost implementation of an existing hands- on laboratory experiment in electronic engineering. International Journal of Engineering Pedagogy 4(4), 1-3 (2014). DOI 10.3991/ijep.v4i4.3707

Ostanin, M., Klimchik, A., 2018. Interactive Robot Programing Using Mixed Reality. IFACPapersOnLine, Volume 51, Issue 22, 2018, Pages 50-55

O’Toole, R., Playter, R., Krummel, T., Blank, W., Cornelius, N., Roberts, W., Bell, W., Raibert, M.: Assessing skill and learning in surgeons and medical students using a force feedback surgical simulator. In: W. Wells, A. Colchester, S. Delp (eds.) Medical Image Computing and ComputerAssisted Interventation - MICCAI'98, Lecture Notes in Computer Science, vol. 1496, pp. 899-909. Springer Berlin Heidelberg (1998). DOI 10.1007/BFb0056278. URL http://dx.doi.org/10.1007/BFb0056278

Pausch, R., Crea, T., Conway, M.: A literature survey for virtual environments: Mili- tary flight simulator visual systems and simulator sickness. Presence: Teleoper. Virtual Environ. 1(3), 344-363 (1992). URL http://dl.acm.org/citation.cfm?id=195923.195962

Petit, A., Marchand, E., Kanani, K.: Augmenting markerless complex 3d objects by combining geometrical and color edge information. In: 2013 IEEE International Symposium on Mixed and Augmented Reality (ISMAR), pp. 287-288 (2013). DOI 10.1109/ISMAR.2013.6671808

Quint, F., Sebastian, K. and Gorecky, D., “A Mixed-reality Learning Environment," Procedia Comput. Sci., vol. 75, no. Vare, pp. 43-48, 2015. 
Santa'S Company: Santa's co. Available from: http://santascompany.blogspot.co.uk/ (2013). [Accessed 14 Feb 2019]

Scholz, J. and Smith, A.N., "Augmented reality: Designing immersive experiences that maximize consumer engagement," Bus. Horiz., vol. 59, no. 2, pp. 149-161, Mar. 2016.

Schwald, B., de Laval, B.: An augmented reality system for training and assistance to maintenance in the industrial context. In: Proc. Int. Conf. Comput. Graphics, Visualiz. Comput. Vision, pp. 425-432. IEEE Computer Society (2003)

Sobota, B., Korecko, S., Hrozek, F.: Mobile mixed reality. In: Emerging eLearning Technologies and Applications (ICETA), 2013 IEEE 11th International Conference on, pp. 355-358 (2013). DOI 10.1109/ICETA.2013.6674458

Tan, H., Pentland, A.: Tactual displays for wearable computing. Personal Technologies 1, 225-230 (1997)

The Ford Motor Company, "Make Way for Holograms: New Mixed Reality Technology Meets Car Design as Ford Tests Microsoft HoloLens Globally," 2017. [Online]. Available: https://media.ford.com/. (Accessed: 5.08.19).

Uhomoibhi, J.O., Palma, J., Alves, P., Restive, T.M., Piteira, M.R., F., O.S., Fernandez, C.: Development of e-learning in higher education and future directions. In: W. Aung, V. Ilic, J. Moscinski, J. Uhomoibhi (eds.) Innovations 2011: World Innovations in Engineering Education and Research, pp. 35-49. iNEER, Potomac (2011)

Wang, S., Mao, Z., Zeng, C., Gong, H., Li, S., Chen, B.: A new method of virtual reality based on unity3d. In: Geoinformatics, 2010 18th International Conference on, pp. 1-5 (2010). DOI 10.1109/GEOINFORMATICS.2010.5567608

Wenguang, L.: Study on characteristic of emerging technology. In: Management and Service Science (MASS), 2011 International Conference on, pp. 1-5 (2011). DOI 10.1109/ICMSS.2011.5997924

White, M., Mourkoussis, N., Darcy, J., Petridis, P., Liarokapis, F., Lister, P., Walczak, K., Wojciechowski, K., Cellary, W., Chmielewski, J., Stawniak, M., Wiza, W., Patel, M., Stevenson, J., Manley, J., Giorgini, F., Sayd, P., Gaspard, F.: Arco - an architecture for digitization, management and presentation of virtual exhibitions. In: Computer Graphics International, pp. 622-625. IEEE, Crete (2004)

Xiao, C., Lifeng, Z.: Implementation of mobile augmented reality based on vuforia and rawajali. In: Software Engineering and Service Science (ICSESS), 2014 5th IEEE International Conference on, pp. 912-915 (2014). DOI 10.1109/ICSESS.2014.6933713

Zahorik, P.: Assessing auditory distance perception using virtual acoustics. Journal of the Acoustical Society of America 111, 1832-1846 (2002) 